Cadernos de História, Belo Horizonte, v. 22, n. 37, Novembro de 2021

DOI: https://doi.org/10.5752/P.2237-8871.2021v22n37p334-352

\title{
O FUTEBOL E O RÁDIO: AUDIÇÃO \\ COLETIVA, REDES NACIONAIS E O ESPORTE NA INCONFIDÊNCIA
}

Luiz OtÁvio CoRrea

Universidade Federal Fluminense

lo.correa@hotmail.com

\section{RESUMO}

Este artigo pretende discutir a relação entre o rádio e o futebol. O caminho escolhido foi a História Social, observando tanto o esporte quanto o meio de comunicação nas suas relações com o seu tempo histórico e com as apropriações realizadas pelas pessoas comuns, através das práticas esportivas e comunicativas que estão imbricadas. Ao pesquisar a relação entre o rádio e o futebol, estudamos também os processos de constituição das tradições, as apropriações dos espaços urbanos e a maneira como os meios de comunicação deslocam as experiências para uma outra dimensão. Na parte final do artigo, retomamos, em outra perspectiva, a pesquisa que realizamos sobre a Rádio Inconfidência, inserindo-a em um contexto histórico mais amplo. $O$ futebol nasce da vivência coletiva e cotidiana, como uma prática de grupos sociais, mas o rádio o transforma em um elemento de reconfiguração da própria experiência das pessoas comuns, consolidando o futebol no Brasil como um elo entre os indivíduos, nas várias mediações que realizam no seu dia a dia. Constatamos que a formação das redes para as transmissões dos jogos levou o futebol para além de sua realidade local e fez com essa prática se desenvolvesse em todo país. Assim, a população distante dos estádios podia agora se apropriar do futebol, à sua maneira, em uma relação mediada pela oralidade, proporcionada pela linguagem do rádio.

Palav ras-chave: Rádio; Futebol; Rádio Inconfidência; Mediações; hegemonia.

Recebido em 28 de novembro de 2020.

Aprovado em 14 de março de 2021. 
Cadernos de História, Belo Horizonte, v. 22, n. 37, Novembro de 2021

DOI: https://doi.org/10.5752/P.2237-8871.2021v22n37p334-352

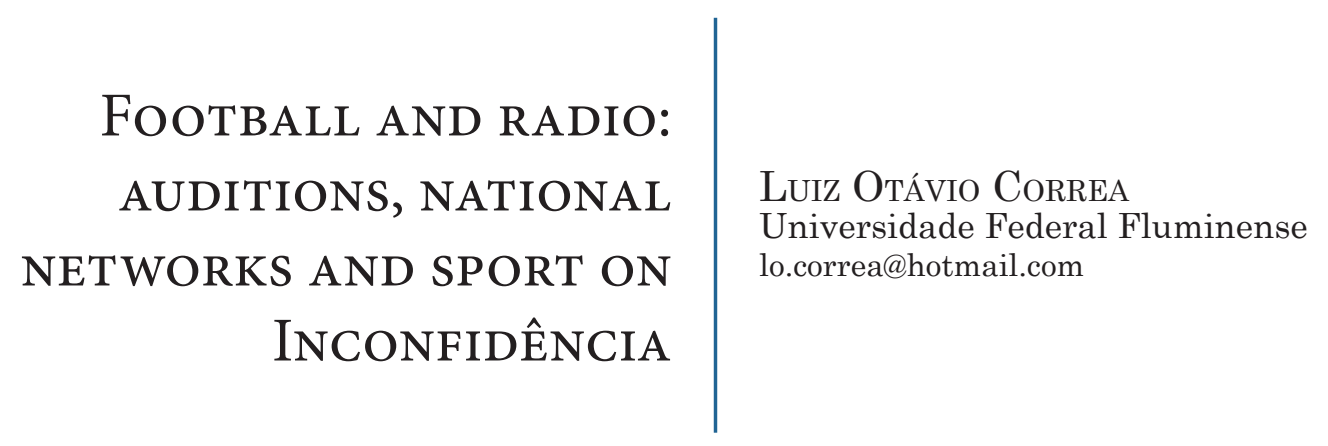

\begin{abstract}
This article aims to discuss the relationship between radio and football. The methodology chosen is concerning Social History, observing the sport as means of communication in their connections with their historical time and with the reception by ordinary people, through the sports and communicative practices that are linked. Researching the relationship between radio and football, we also studied the processes of constitution of traditions, the appropriation of urban spaces and the way in which the media move experiences to another dimension. In the end of this article, we resumed, from another perspective, the research we carried out about Rádio Inconfidência, linking it to a broader historical context. Football arises from collective and everyday experience, as a practice of social groups, but the radio changed it into an element of adaptation of ordinary people's experiences; it strengthens football in Brazil as a bond between individuals, in the accomplishments they carry out in their day-to-day lives. We found out that the formation of networks for broadcasts contributed to the football development and propitiated its expansion throughout the country. Therefore, the population outside stadiums began to enjoy football in their own way, in a relationship mediated by the orality provided by the language of the radio.
\end{abstract}

Keywords: Radio; Football; Rádio Inconfidência; Mediations; hegemony. 


\section{INTRODUÇÃo}

A história social costuma deslocar o seu olhar para as praças, tentando ver as ações daqueles que muitas vezes não são visíveis. No caso da prática da audição do rádio, a pesquisa histórica poderia contribuir para o entendimento de como a vida dos ouvintes foi modificada pela presença desse meio eletrônico. O entrelaçamento da história do processo de audição popular das emissoras de rádio com a história do futebol pode permitir a compreensão de como a prática e o consumo desse esporte foram modificados pela presença desse meio de comunicação. A partir dessa metodologia é possível entender também como os ouvintes passaram a vivenciar, a distância, as transmissões dos jogos, imaginando o que estava acontecendo nos estádios, através da mágica oralidade proporcionada pela maneira como os radialistas construíam as paisagens sonoras.

Vendo o mundo a partir da geral, ${ }^{1}$ poderíamos pensar que a prática esportiva é também uma relação de apropriação e que o futebol teve as suas origens em várias mediações culturais (nas ruas, praças e portos) e não somente no monopólio excludente pretendido pelas elites europeias que formalizaram a sua inserção no Brasil (SILVA, 2006, p. 28). Este trabalho (de apropriação e construção das representações sobre "de quem" é o futebol) denota as tensões da própria noção do que é ser brasileiro. Esse processo constitui-se como uma relação dialética, que envolve outras mediações, tais como a formação social dos clubes, a presença do futebol na imprensa e, no nosso caso, a novidade da mediação pelo rádio, que se tornaria importante no Brasil, nos anos de 1930. Nesse tempo, esse meio transformou-se em um elemento da modernidade pretendida pelo regime varguista que chegou ao governo naquele ano e o futebol, tal como o samba, em um elemento da nacionalidade. Todos eles juntos denotam uma nova realidade constituída, que queria se impor como uma nova hegemonia, uma nova forma de se pensar uma forjada identidade nacional. ${ }^{2}$

O objetivo deste trabalho era, inicialmente, apresentar os resultados da pesquisa de doutoramento, que se findou a pouco, sobre a Rádio Inconfidência de Minas Gerais. Mas, ao revisitar as fontes, outras questões foram aparecendo e, dessa forma, o artigo tomou um rumo diferente do que havia sido pensado anteriormente. A proposta anterior, tinha como ponto de partida o esporte nessa emissora. A Rádio Inconfidência continua presente, mas

1 Termo que designava o local onde as camadas mais pobres eram mais presentes nos estádios por ter preço do ingresso mais acessível. Os torcedores da geral costumavam ser chamados de geraldinos, em determinados estádios.

$2 \mathrm{O}$ conceito de hegemonia usado neste artigo remonta à tradição gramsciana, $(2017,2004)$ já muito debatida e que consideramos não haver tempo para uma discussão sistemática neste artigo. Mas seria interessante dizer que procuramos entender como a hegemonia se constitui como um processo histórico, seguindo os passos de E.P Thompson (2012), bem como os meios de comunicação são responsáveis pela reorganização da vida das pessoas e dos seus modos de vida, como foi no caso da urbanização no Brasil a partir da década de 1930. Portanto, temos em mente que o conceito de hegemonia em Gramsci refere-se à construção das concepções de mundo, no jogo político do controle sobre o senso comum pelos grupos dominantes. Partimos do pressuposto de que o processo de urbanização ocorrido no Brasil durante o século XX é também um momento de reorganização dos modos de vida e que o rádio contribui para tal fenômeno, o da educação das classes trabalhadoras para a vivência nas fábricas e para a reorganização do seu lazer, momento em que o futebol se insere. Essa organização da realidade pelos grupos de poder dirigentes pressupõe a disciplinarização e controle sobre corpos e mentes (THOMPSON, 2012). Mas é também um processo aberto para subversões e conflitos, pois é feito pela ação das pessoas nos processos históricos. O futebol e o rádio são mediadores da constituição do senso comum, mas também espaços de conflitos e mudanças, como nos mostrou Euclides Couto, nas suas pesquisas (2014), no caso do primeiro elemento mediador. Portanto, o futebol e o rádio não podem ser tratados como um entretenimento vazio, mas como espaços de disputa e reverberação dos conflitos das sociedades, das classes e dos grupos de poder. Ver: Martín-Barbero (1997) e Williams (2011). 
resolvemos, agora, conjugá-la ao atrelamento do futebol ao rádio, delimitando a pesquisa de 1929 a 1940. Mais do que pensar na rádio em si, pretendemos observar como as pessoas comuns foram aderindo a este esporte, à medida que ele ia sendo transmitido para todo o país, pelo rádio.

As fontes consultadas permitiram constatar que, nos anos de 1930, o futebol já era capaz de reunir multidões nas ruas, primeiro, por causa dos jogos da seleção nacional brasileira e, segundo, pelo crescimento dos clubes que se profissionalizaram naquela década. Não estamos supondo que haja uma relação de causa e efeito entre a popularização do futebol e o desenvolvimento do rádio. Entre esses elementos mediadores, existe uma rede de outros que se coadunam, um processo histórico e amplo em que a cultura tem um papel fundamental. Como nos ensinou Raymond Willians e Jesús Martín-Barbero, as relações entre os meios de comunicação e a sociedade se dão em uma relação dialética e envolvem processos de negociação amplos, que começam nas ruas, nas praças, nos bares, no lar, na vida cotidiana das pessoas. As práticas esportivas, as práticas de audição, bem como o desenvolvimento das indústrias em torno desses fenômenos foram potencializadas e deslocadas para além do local com o desenvolvimento do rádio. Mas a popularização desse esporte não se iniciou com esse meio de comunicação eletrônico, apenas foi deslocada para além do local em que se dava, ganhando outros contornos. ${ }^{3} \mathrm{Na}$ década de 1930, alinhou-se a esse processo a chegada de Vargas ao poder, fenômeno que reconfigura o rádio e o futebol como elementos presentes na constituição da nacionalidade nas representações da brasilidade.

É preciso dizer que utilizamos recortes dos jornais da época como fontes para a nossa pesquisa. Existem raros arquivos sonoros sobre o tema e resolveu-se então ler o rádio através da sua reverberação nos jornais da época, que funcionava de maneira circular com o rádio, meio eletrônico que se firmava no Brasil no momento. Os recortes escolhidos nos jornais são os de maior circulação, mas não excluímos aqueles de pequena tiragem, quando ofereciam pistas interessantes para a nossa pesquisa. Há, logicamente, uma prevalência dos jornais do sudeste, o que denota uma limitação na pesquisa, por nós reconhecida, neste texto. Vale a pena pensar no que estava ocorrendo no resto do país, para além do eixo Rio-São Paulo ou Minas Gerais.

É necessário ressaltar a importância da Hemeroteca Digital da Biblioteca Nacional para a pesquisa, pois ela permitiu o cruzamento dos dados e das perguntas que fazíamos para este texto. Tínhamos em mente, como deve ser toda operação historiográfica, que os jornais proporcionariam observar o rádio daquela época que escolhemos, mas tanto um meio quanto o outro foram lidos de maneira crítica, inserindo-os na lógica industrial da produção de notícias, na forma que ela tomava em seu tempo. ${ }^{4}$

\section{AS PRIMEIRAS EXPERIÊNCIAS}

A trajetória do artigo começa em 1929, quando as transmissões das partidas do futebol começam a aparecer nos jornais da época, mesmo antes da instauração do governo de Vargas.

3 Cf. AMARAL; COUTO (2019).

4 "O documento não é inócuo. É, antes de mais nada, o resultado de uma montagem, consciente ou inconsciente, das sociedades que o produziram, mas também das épocas sucessivas durantes as quais continuou a viver, talvez esquecido, durante as quais continuou a ser manipulado, ainda que pelo silêncio.” (LE GOFF, 1996.) 
Não procuramos fazer o trabalho de detetive para saber, por exemplo, qual foi a primeira transmissão radiofônica do futebol. Partimos do que diziam as nossas fontes consultadas, os jornais da época, quando as transmissões, portanto, ganharam importância na imprensa. Pode ser que alguma outra data anterior seja a da primeira transmissão, mas para os propósitos deste artigo, é mais relevante entender quando o futebol e o rádio começam a se tornar elementos que transcendiam os seus locais de origem para se tornarem elementos de massa e da nacionalidade.

Nas fontes que consultamos, as primeiras transmissões de futebol passam a acontecer e a reverberar nos jornais a partir de 1929. Lia Calabre (2002) apontou o ano de 1927 como a primeira transmissão realizada pelo rádio; já Edileuza Soares(1994) nos informa que as primeiras experiências de notícias sobre o futebol no rádio já começam a aparecer no ano de 1924. No entanto, Soares nos diz também que a narração pioneira, que vai marcar o início da maneira como se passaria a narrar os jogos, se dá em 1931, quando se criou um segmento, um gênero específico, quando o rádio deixou de ser um "repetidor de notícias". (SOARES, 1994, p. 13)

Embora as transmissões ainda possuíssem um formato informativo, as notícias eram capazes de levar grande número de pessoas às ruas. Os alto-falantes colocados nas ruas para se ouvir os jogos pelos meios de comunicação de massa da época nos permitiriam dizer que, mesmo não tendo um formato de narração que conhecemos hoje, as rádios eram capazes de mobilizar a aglomeração de pessoas nas ruas; isso ocorria em várias cidades do Brasil durante os jogos da seleção nacional e também nos estaduais. Partimos da perspectiva de que as transmissões mediadas tinham um relevante impacto nas ruas e praças das cidades e que o rádio alcançava, já no final da década de 1920, públicos ampliados, sem pretender entrar na polêmica sobre o pioneirismo da primeira transmissão que, para os propósitos deste artigo, não é o mais importante.

Como exemplo desse impacto, parece ter causado uma grande expectativa a possibilidade da transmissão do jogo, pela Rádio Club do Brasil, ${ }^{5}$ de partidas entre clubes cariocas e agremiações internacionais, em julho de $1929,{ }^{6}$ ou entre a seleção paulista e o time do Rampla Juniores, em fevereiro do mesmo ano. Segundo o relato do jornal Diário Carioca a irradiação realizada pela emissora resultou em inúmeros pedidos, feitos por telefone, carta, telegrama, solicitando à rádio uma nova transmissão. O jogo foi retransmitido pela Rádio Educadora Paulista ${ }^{7}$ e essa emissora entrou em contato posterior com a rádio carioca, relatando, já no final da década de 1920, a grande aglomeração de pessoas nos pontos de retransmissão pelos alto-falantes para acompanhar as chamadas "pugnas de football”. Como dizia o jornal do Rio de Janeiro:

uma multidão incaculável assistia em São Paulo o desenrolar da pugna descripta com fidelidade pelo speaker da rádio Club do Brasil que mereceu por isso calorosos cumprimentos. $\mathrm{Na}$ frente da sede da Rádio Club outra multidão formidável assistia com vivo enthusiamo o referido jogo que era transmitido à rua por possantes alto-falantes. Enquanto isso um representante da Agência Americana e outro de "La nación" de Buenos Aires transmitiam da sède

5 A Rádio Club foi uma das primeiras emissoras do Rio de Janeiro, tendo sido inaugurada em 1º de outubro de 1924. Foi pioneira nas transmissões esportivas como estamos tentando demonstrar nesse texto.

6 MAIS um goal da Radio Club do Brasil. Jornal do Brasil, Rio de Janeiro, ano 97, n. 179, p. 13, 27 julho, 1929.

7 Rádio que começou as suas transmissões em 30 de novembro de 1923 em São Paulo. A Rádio Club e a Educadora de

São Paulo também foram pioneiras nas transmissões em rede, nas transmissões esportivas. 
do Rádio Club do Brasil a descripção completa do jogo para os seus jornaes. ${ }^{8}$

Além do impacto nas cidades, que pode ser notado na matéria, outro indício importante pode ser detectado, que é o fato de que os meios de comunicação começavam a se entrelaçar e a reverberar uns nos outros, uma retroalimentação que iria desembocar na formação de indústrias midiáticas, mais consolidadas na década seguinte. Um outro aspecto é que as irradiações já chegavam a outros países, como nesse caso citado.

As fontes que consultamos também nos sugerem que alguns clubes de futebol demonstravam insatisfação em relação às irradiações esportivas, com receio de perder a receita que resultava da presença das pessoas nos estádios. Foi o caso, por exemplo, além de outros que encontramos, da proibição da Rádio Club de transmitir a partida entre a seleção carioca e o time italiano do Bolonha, no estádio do Botafogo. O clube não permitiu sequer a retransmissão para São Paulo, pela Rádio Educadora Paulista. ${ }^{9}$

Em dezembro, a Rádio Club obteve a autorização para a transmissão, pela Confederação Brasileira de Desportos (CBD), do jogo entre a seleção carioca e a paulista e, dessa forma, dizia o jornal A Batalha, "teremos pelo rádio o desenrolar da sensacional partida", que poderia definir o título de campeão brasileiro do ano de 1929. A transmissão entre as seleções do Rio de Janeiro e São Paulo se deu por um sistema de telefonia que mantinha os paulistas informados do que ocorria no Rio de Janeiro por ocasião do jogo, através de um sistema de alto-falantes instalados no estádio do Palmeiras. ${ }^{10} \mathrm{~A}$ informação não vinha por rádio, mas pode ser que tivesse sido retransmitida pelas rádios locais, já que era uma iniciativa da Associação dos Chronistas sportivos de São Paulo. ${ }^{11}$

O conflito entre as emissoras e os clubes de futebol pelo controle das transmissões ligava-se ao fato de que as partidas deste esporte começavam a ser vistas como um negócio, apesar das dificuldades instituídas pelo decreto 16.557, de 1924, que limitava a publicidade nas emissoras e a comercialização dos reclames, ${ }^{12}$ embora elas ocorressem em 1929, sendo que as próprias emissoras de rádio anunciavam os espaços publicitários nos jornais, como no evento da irradiação da partida entre as seleções paulistas e cariocas, onde pudemos constatar os valores cobrados para a publicidade nos jogos e como eram classificados na ordem de importância: "os preços para os reclames nessa irradiação especial são os seguintes: na vesperal $20 \$ 000$ por vez e no football $40 \$ 000$ por vez."13

De maneira geral, as fontes consultadas indicam que as transmissões eram bem-vistas pelos jornais da época. Nesse aspecto, por exemplo, o texto do Diário Carioca em 1929, criticava os clubes por não permitirem que a Rádio Club pudesse realizar a irradiação da

8 A ÚLTIMA transmissão do jogo internacional de Futebol. Diário Carioca, Rio de Janeiro, n. 190, p. 4, 24 fevereiro,1929. Disponível em: http://memoria.bn.br/DocReader/093092_01/2183. Acesso em:

9 SEM fio. A noite. Rio de Janeiro, n. 6354, p. 4, 28 julho, 1929.

$10 \mathrm{O}$ telefone, que tinha por finalidade o uso privado, naquele momento tinha seu uso amplificado por meios de comunicação que expandiam o seu uso. O uso do meio depende das circunstâncias históricas e do seu desenvolvimento em uma situação histórica, na relação com a sociedade. (WILLIAMS, POOL,1992)

11 IRRADIAÇÃO do jogo Rio São Paulo. Correio Paulistano. São Paulo, n. 23727, p. 12, 4 dezembro, 1929. Disponível em: http://memoria.bn.br/DocReader/090972_07/38852. Acesso em: 24 nov. 2020.

12 Como nos informa Lia Calabre, "O decreto-lei n.16.657 (15.11.1924) determinava que "O Governo reserva para si o direito de permitir a difusão rádio-telephonica (broad-casting) de annúncios e reclames commerciais”. (CALABRE, 2002)

13 SEM fio. A noite. Rio de Janeiro, n. 06509, p. 4, 28 de dezembro, 1929. 
partida diretamente dos estádios, nem sequer para outros estados, realizando "a descripção das phases da empolgante partida internacional". Como dizia o jornal, a negativa tinha "ordem financeira”, ou seja, o receio de que a arrecadação do certame ficasse prejudicada pela transmissão das rádios. ${ }^{14}$

O jornal defendia as irradiações, afirmando que a multidão não deixaria de "ir assistil-a para ficar em casa, ouvindo pelo rádio". Ao contrário do que achavam os clubes, defendia o noticioso, o rádio funcionaria como um elemento propagador da prática esportiva, pois quem nunca viu uma partida, ficaria curioso por vê-la e seria, na perspectiva da nossa fonte, um "futuro expectador". A irradiação faria, portanto, a propaganda do futebol e teria o papel “civilizador" de elevação desse esporte. Na visão do escritor do texto, o Brasil estava atrasado em relação a outros países, pois havia apenas quatro estações de broadcasting no Rio de Janeiro e que eram poucos os "amadores, que têm apparelhos em suas casas, não chegam a 70 mil para uma cidade de 2 milhões de habitantes" ${ }^{15}$.

O discurso de defesa das transmissões dos jogos pelo rádio não incluía o fato de que as emissoras e a própria imprensa começavam a ver o futebol como um negócio e que se vendia, na programação, espaços para os reclames que viabilizariam comercialmente as transmissões e pagariam os custos telefônicos da formação das redes. Mas os processos sociais e políticos que se desenvolveram durante a década seguinte iriam reforçar o argumento de que as transmissões iriam fazer propagar o futebol para além dos círculos em que eram praticados localmente, para se tornar um esporte de interesse nacional. O desenvolvimento do rádio reorganizou a experiência cotidiana dos seus ouvintes, o senso comum e os seus costumes e, concomitante com o crescimento e popularização do futebol, passaram a ser também experiências deslocadas do seu local.

\section{O QUADRO A PARTIR DOS ANOS 1930}

Durante o governo Vargas, foi se constituindo uma nova representação de Brasil, propagada pelos meios de comunicação de massa e pelos elementos mediadores presentes no processo de formatação de um novo contexto. No caso do rádio, Getúlio Vargas e os empresários brasileiros vinham, pela influência do que acontecia na Alemanha naquele momento, se articulando para criar um sistema midiático que pudesse ser capaz de controlar simbolicamente a sociedade. Havia a ideia de que se se utilizassem "corretamente" os meios de comunicação, as ferramentas para um tipo de modernização autoritária poderiam ser criadas (baseadas nas ideias de harmonia social, sem conflitos e comandada pelas elites) ao promover o envolvimento emocional das multidões. No período varguista, o meio eletrônico rádio foi usado de várias maneiras como elemento de poder, como no caso da estatal Rádio Inconfidência, ou indiretamente, como se constituíram as rádios privadas do conglomerado de Assis Chateaubriand. ${ }^{16}$

14 A MOMENTOSA questão da irradiação das partidas de futebol. Diário Carioca, Rio de Janeiro, n. 308, p.6, 26 julho de 1929.

15 op.cit.

16 Assis Chateaubriand elogiava na época a propaganda nazista que, na sua concepção tinha o poder de gerar uma hipnose coletiva. Não nos cabe problematizar a questão do tipo de regime instaurado pelo Estado Novo, discussão já realizada por outros historiadores do período, como é o caso de Maria Helena Capelato. Concordamos que existia uma predisposição para a implementação de certas políticas culturais autoritárias no regime brasileiro, apesar das diferenças entre o Estado Novo, a partir de 1937, e os regimes totalitários europeus (CAPELATO, 2009). 
As rádios espalhadas pelo Brasil teriam, nessa perspectiva, a missão de criar as condições para a unidade nacional, em torno do Varguismo. Os meios de comunicação eletrônicos representavam a modernidade e foram usados politicamente, em uma clara manifestação do autoritarismo, sendo o rádio uma fonte de violência simbólica.

As emissoras de rádio (ou de televisão, um pouco mais tarde) cumpriam o papel de educadoras (COTA, 2016), na constituição do senso comum, quando pretendiam se constituir como a voz do conjunto da sociedade. No entanto, elas se modificavam em razão dos contextos históricos e da negociação com a sociedade, criando, em determinadas circunstâncias, condições para a constituição de hegemonias discursivas (HALL,2003).

Também foi nesse quadro que se deu a profissionalização do futebol. Em 1930, o futebol já era uma realidade como um fenômeno de massa (COSTA, 2006, p. 107), mas ele só se profissionalizaria em 1933 (SILVA, 2006, p. 30; AGOSTINHO, 2006, p.68). A profissionalização do esporte em Minas Gerais ocorreu também naquele ano, em que se deu a realização do primeiro campeonato profissional nesse estado (MOURA, 2012).

O futebol passou a representar um elo com o corpo nacional, integrado e sem conflitos, constituindo-se como uma comunidade nacional. (PARADA, 2006, p. 155). O esporte era capaz de aglutinar elementos da nacionalidade e tornou-se ainda mais popular naquela década de 1930 (COELHO, 2006, p. 242); esse fenômeno forjou uma nova tradição, juntamente com a música popular, com o rádio (os meios de comunicação, de uma maneira geral), uma nova legitimidade social e com todos os elementos da cultura popular daquele período, no período que se inicia com Getúlio Vargas no poder.

As teias do social se consolidam nas mediações e nesse trabalho escolhemos associar duas delas. Este artigo tem mais a levantar questões do que tentar fechá-las, na construção dos sentidos sociais do recorte temporal escolhido. Poderíamos analisar, por exemplo, como a música popular teve papel importante na construção do senso comum urbano no Brasil a partir da década de 1930, na relação entre o samba, o futebol e a nacionalidade, manifestações culturais espalhadas por todo país através das ondas do rádio. Mas vamos nos deter na construção da relação entre o futebol e o rádio nesse momento, abrindo as portas para outras possibilidades.

Como afirma Euclides Couto (2014), o rádio, na década de 1930, foi responsável pela articulação entre o torcedor, os clubes e a seleção brasileira; essa mediação faz parte de um processo histórico amplo que envolvia a construção de uma representação de Brasil pretendida pelo Varguismo. Portanto, o meio de comunicação rádio é um meio de produção social tal como é o futebol e ambos se entrelaçam no Brasil. O futebol e o rádio fazem parte, hoje, de uma indústria esportiva, mas também foram práticas sociais que antecedem o desenvolvimento da sua profissionalização, tanto da mídia eletrônica rádio quanto do esporte, sendo, depois, apropriados pelas indústrias culturais que se desenvolveram, em conjunto, nas décadas seguintes.

Por isso a importância de se estudar esses fenômenos de maneira imbricada e, mais do que isso, ver como se tornaram elementos do que passou a ser considerado como popular ao longo daquela década e das seguintes. A importância do Estado nesse processo é fato já comprovado por outros pesquisadores do assunto, mas o que queremos entender, em outro caminho, são os sentidos socialmente constituídos. Isso deve ser feito tendo em vista a relação 
entre o futebol, o rádio e os mediadores sociais da época, na maneira como se constituem como práticas sociais das massas e como estas ressignificam essa prática esportiva; isso é percebido, a partir das experiências mediadas pelo rádio, não somente no espaço privado, mas nas práticas coletivas de audição, como eram comuns na época.

A partir da década de 1930, depois da chegada de Getúlio Vargas ao poder, o Estado vai organizar esse processo e, tanto o futebol quanto o rádio, aliados a outros elementos mediadores, contribuiriam para a constituição da legitimação de uma modernização autoritária que tinha como centro o próprio Estado brasileiro. O processo que se iniciava contribuiria para que o futebol ganhasse uma outra dimensão como esporte, popularizando-se como um elemento da cultura brasileira.

O indício que recolhemos, que indicava o número de 70 mil aparelhos na capital do país no ano de 1929, poderia nos permitir medir a extensão do alcance do rádio no Brasil naquele momento ou constatar um possível baixo impacto que o rádio poderia ter em relação ao número da população que o consumia naquela cidade. Mas também poderíamos pensar sobre esses dados, já que, tomando-os como supostamente corretos, não dizem sobre o alcance da audição coletiva que o rádio proporcionava nos bares, cafés ou mesmo nas casas mais abertas às visitas nas horas das transmissões dos jogos. Por exemplo, em 1930 os clubes esportivos disponibilizavam rádios para audição coletiva da irradiação dos jogos da seleção brasileira, no episódio da Copa do Mundo do Uruguai. Os clubes não eram abertos a todos, na disponibilização de tal audição coletiva, determinando um certo nível de exclusão no processo de escuta. Mas a existência desse fenômeno nos indica que as audições coletivas representavam um contingente relevante de "atingidos" pelas emissoras de rádio. ${ }^{17}$

Um outro aspecto importante é que os clubes foram se abrindo para as irradiações. Em 1931, o Botafogo, antes resistente às locuções, inaugurava seu próprio sistema de altofalantes, que divertiriam os torcedores presentes nos estádios executando músicas, antes e durante os intervalos. ${ }^{18}$ Em 1932, a Rádio Club já transmitia as partidas do campeonato carioca de futebol entre os times do Botafogo e do Bonsucesso. ${ }^{19}$

Também é importante dizer que em outros estados as irradiações começavam a ocorrer. O primeiro indício de transmissão que encontramos em Minas Gerais foi em 1932. Naquele ano, os jogos entre o Vasco e o Athletico Mineiro eram transmitidos pela Rádio Mineira, a primeira de Belo Horizonte, e retransmitidos por algumas rádios do Rio de Janeiro, como a Rádio Guanabara. ${ }^{20}$ A Rádio Mineira, fundada em 1927, parece ter sido a pioneira na transmissão de eventos esportivos nesse estado. Naquele ano de 1932, ela também retransmitia a rede que irradiava a Taça Rio Branco, em parceria com o Jornal Correio da Manhã e a Rádio Sociedade do Rio de Janeiro, diretamente de Montevideu. ${ }^{21}$ A Companhia Telephônica Brasileira havia disponibilizado uma linha para a transmissão, por telefone, para o Brasil, através da Rádio Guanabara e da Rádio Sociedade. O sistema conectava, por telefone, a Rádio Mineira, em Belo Horizonte. Já nessa época, no centro da capital do país, foram colocados alto-falantes para a audição pública das emissoras cariocas:

17 CAMPEONATO mundial de Football. Correio da manhã. Rio de Janeiro, n.10906, p. 10, 12 de julho 1930.

18 MISCELÂNEA sportiva. Correio da manhã, Rio de Janeiro, n.11127, p. 8.28 de março de 1931.

19 SEM fio. Correio da manhã, Rio de Janeiro, n. 11601, 2 outubro 1932.

20 SEM fio. Correio da manhã, Rio de Janeiro, n. 11601, 2 outubro 1932.

21 IRRADIAÇÃO do Match. Correio da Manhã, Rio de janeiro, n. 11654, 2 dezembro 1932. 
O correio da Manhã e a UTB (União Telegráfica Brasileira), em collaboração com a Cia. Telegráphica Brasileira, controlados pelos cabos submarinos Italcable, organizam um serviço pelo telephone internacional, que permittirá ao público ouvir a descripção do match, feita diretamente do stadium centenário, pela estação de rádio sociedade do Rio de Janeiro. ${ }^{22}$

Os relatos posteriores ao jogo nos informavam que o som advindo da Rádio Guanabara havia chegado de maneira límpida à Belo Horizonte através da retransmissão em rede, pela Rádio Mineira. Como no Rio de Janeiro, as pessoas foram às ruas para escutar a irradiação pelos alto-falantes e o Correio da Manhã relatava a presença de 10.000 pessoas em Belo Horizonte. O relato também dizia da audição no interior de Minas Gerais, pelo canal da Rádio Mineira. Nesse caso, a transmissão era mais uma descrição das informações e o formato de narração iria ser desenvolvido ao longo da década de 1930, até chegarmos à moderna locução de eventos esportivos. ${ }^{23}$

IMAgem 1- População ACOMPANHANdo o Jogo Pelos Alto-FAlantes em 1932.

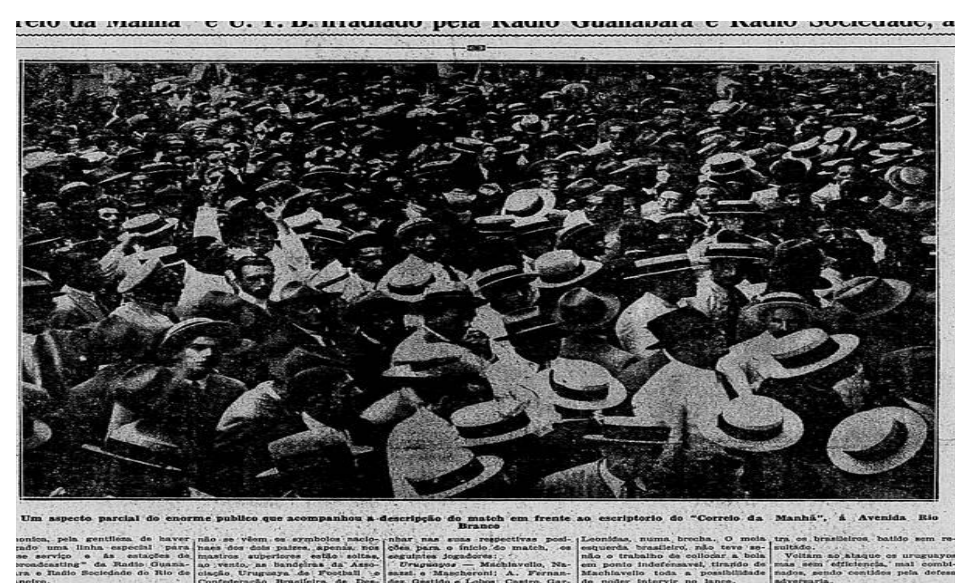

Fonte: Correio da Manhã. 6 de dezembro de 1932

A partir de meados dos anos de 1930, seriam vários os estabelecimentos de redes, não somente para a transmissão de jogos da seleção, mas também para a dos jogos dos clubes, que ganhavam projeção para além dos seus estados, depois do processo de profissionalização ocorrido no início daquela década. ${ }^{24}$ No ano de 1937, a Rádio Nacional e a Rádio Club do Rio de Janeiro, estabeleciam uma parceria para a transmissão dos jogos dos times da cidade. A formação das redes foi importantíssima neste processo de expansão do futebol para além dos limites locais e os times passavam a ser conhecidos em outros lugares também.

22 EM FRENTE ao Correio da Manhã. Correio da manhã. Rio de Janeiro, n. 11662, 11 dezembro 1932. 23 Os brasileiros derrotam os uruguayos no stadium Centenario por 2x1. Correio da Manhã. Rio de Janeiro, n.11657, 6 dezembro 1932. Disponível em: http://memoria.bn.br/DocReader/089842_04/14292. Acesso em: 24 nov. 2020. 24 PR2. Gazeta de Notícias. Rio de Janeiro, n. 192. 13 agosto, 1939. Disponível em: http://memoria.bn.br/ DocReader/103730_06/23126. Acesso em: 24 nov. 2020. 
IMAGEM 2- ANÚNCIO DA TRANSMISSÃo DOS MATCHES

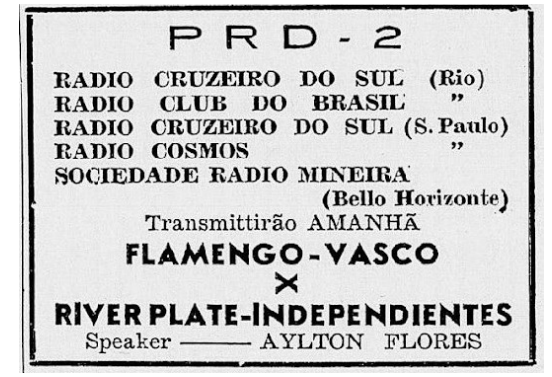

Fonte: Gazeta de notícias. 13 de agosto de 1939

O rádio estava reconfigurando o "football", transformando-o em um esporte nacional, acompanhando o processo de modernização autoritária que ocorreria durante o período que estudamos, os anos de 1930 e início dos 40. Mas não era somente o "football" que atraía a atenção dos ouvintes das rádios. Em 1937 várias emissoras transmitiram direto do "Circuito da Gávea" o "Grande prêmio da cidade do Rio de Janeiro" de automobilismo. Segundo os jornais da época, foi montada uma estrutura de comunicação, via telefone, que oferecia às emissoras assinantes 86 linhas diretas disponibilizadas pela Companhia Telephônica Brasileira para o evento, que permitiu a instalação de 115 aparelhos de telefones que serviam às rádios. A Rádio Inconfidência transmitiu o evento para Minas Gerais, bem como a Rádio Guarany de Belo Horizonte. ${ }^{25}$

As representações da nação do varguismo tinham seus tentáculos sobre os elementos mediadores e o futebol tinha um papel importante (como na Copa do Mundo de 1938), quando foi usado politicamente. No dia 16 de julho daquele ano, o jornal "Correio Paulistano" noticiava que o presidente Getúlio Vargas e Oswaldo Aranha haviam acompanhado pelo rádio a vitória da seleção brasileira sobre a Tchecoslováquia, irradiada para o Brasil pela Rádio Club do Brasil, na voz de Gagliano Neto, speaker da emissora. ${ }^{26}$ No final do ano de 1938, a irradiação da Copa do Mundo para o Brasil havia estabelecido um novo padrão de transmissão que iria se prolongar pelos anos seguintes. A maneira informativa do início da década ia sendo substituída pelo desenvolvimento da especificidade da linguagem do rádio, como aconteceu com o jornalismo que foi remodelado pelo padrão do programa Reporter Esso, um pouco mais tarde. Gagliano Netto parece ter sido importante na nova maneira de se narrar um jogo de futebol, ao menos na visão de certos jornais da época. ${ }^{27}$

\section{A SEGUNDA METADE DA DÉCADA E A RÁdIo INCONFIDÊNCIA}

Daqui para frente, vamos falar um pouco sobre a Rádio Inconfidência, procurando observar como esse fenômeno geral que apresentamos anteriormente pôde ser notado nessa emissora. A rádio foi fundada no ano de 1936 e se inseria, a partir daquele momento, no quadro daquelas primeiras rádios brasileiras. Em Minas Gerais, numa dimensão mais regional, Benedito Valadares queria fazer da Rádio Inconfidência um elo entre a capital e o interior.

A Rádio Inconfidência fez a cobertura da Copa de 1938, dois anos depois de ter sido

25 IRRADIAÇÃO será feita em 25 emissoras. Pequeno Jornal: Jornal Pequeno. Pernambuco, n.133, 15 junho, 1938. 26 A IRRADIAÇÃO do jogo. Correio Paulistano. São Paulo, n. 25226, p. 20, 5 junho, 1938.

27 O CAMPEÃO dos speakeres. Carioca. Rio de Janeiro, n. 145, p. 40. 
inaugurada e deu ênfase, nas suas reportagens, aos mineiros que faziam parte dos convocados da seleção nacional, colocando os jogadores Niginho (Leonídio Fantoni), Perácio (José Perácio Berjun) e Zezé Procópio para conversarem ao vivo com seus parentes no Brasil. ${ }^{28}$ Em 15 de julho de 1938, o Jornal do Commércio anunciava, dessa forma, a transmissão da Rádio Inconfidência em Belo Horizonte:

O jogo de hoje do campeonato mundial será irradiado em Minas Gerais pela Rádio Inconfidência. Com viva emoção, verdadeiras multidões se aglomeram nos cafés e bares, e em todos os pontos onde há alto-falantes. O grande encontro de hoje está sendo aguardado com o máximo interesse. ${ }^{29}$

A Inconfidência funcionava, portanto, como um nó aglutinador de certos eventos esportivos, como foi no caso da Copa de 1938. Um ponto interessante é que, na narrativa construída pelo jornal, a cidade e as multidões viviam a Copa do Mundo em Belo Horizonte como um evento de grande importância, havendo uma grande mobilização popular como ocorreu em outras cidades. O futebol ganhava a dimensão da própria incorporação da nacionalidade no Estado Novo que buscava uma legitimação nos seus mediadores culturais. No texto acima, além da descrição do fato em si, buscamos entender os sentimentos daquela época e a vivência compartilhada pela nação em relação ao futebol, que foi sendo alimentado ao longo do século XX. Temos, então, um bom exemplo do enquadramento pretendido pelo Estado, propagado pelos alto-falantes das emissoras de rádio e apropriado de maneira diferenciada pela população.

Vejamos um trecho de outro jornal, que também poderia nos ajudar a compreender esse sentimento em Belo Horizonte, a partir do enquadramento do futebol como um elemento da nacionalidade, no evento transmitido pela Rádio Inconfidência:

\begin{abstract}
Afim de proporcionar aos funccionarios do Estado opportunidade de acompanharem pelo rádio, as notícias da partida de hoje, do campeonato mundial de foot-ball, o governador determinou que o horário das repartições públicas estaduais, hoje, são os mesmos dos sabbados, isto é, sómente pela manhã. ${ }^{30}$
\end{abstract}

Em Minas Gerais, o governador Benedito Valadares fazia da Rádio Inconfidência um instrumento de poder e de conexão com o interior. A Copa do Mundo juntava-se, nesse aspecto, às transmissões das festividades da Semana Santa e das festas populares mineiras. Nesse momento, a Rádio Inconfidência chamava-se de $A$ Voz de Minas e, um pouco mais tarde, ela passou a se representar como "O Gigante do Ar". ${ }^{31}$

As multidões inseridas nas políticas culturais do Estado Novo, na maneira como estudou Maria Helena Capelato, tinham no Estado um ponto centralizador. Em uma dimensão regional,

28 PERÁCIO, Niginho e Zezé falarão, hoje, com suas famílias. Jornal A Noite. 15 julho de 1938.

29 O INTERESSE nos Estados. Jornal do Commércio, p. 9, 15 de junho de 1938.

30 FECHARAM cedo as repartições. Correio da manhã. Rio de Janeiro, N.13373, p.6. 15 junho, 1938.

31 Como analisamos na tese sobre essa emissora, em alguns momentos, a rádio buscava uma autorrepresentação na qual essa se fundia ao que era ser mineiro, o que se traduzia no seu slogan desde a sua fase inicial: A Voz de Minas. À medida que a rádio foi ganhando potência nas décadas seguintes, a imagem da emissora passou a ser representada como "gigante", como era na década de 1950, durante o governo de Juscelino Kubitschek. O slogan deixou de ser, paulatinamente A Voz de Minas e passou a ser, hegemonicamente, O Gigante do Ar. Duas representações da identidade, cujos significados foram forjados em contextos específicos, mas usados de maneiras diversas, dependendo momento em que se inseria. Nos anos de 1960 o departamento esportivo acresceu ao Gigante do Ar, a ideia de que a Inconfidência era a rádio padrão da América, ou, da maneira como era dito pelo importante jornalista esportivo Jairo Anatólio Lima: "Rádio Inconfidência, emissora padrão do continente, o gigante do ar." 
em Minas Gerais a Rádio Inconfidência, estatal, passou a ter um papel relevante como teria a Rádio Nacional um pouco mais tarde. É preciso lembrar que, naquele momento, a Nacional já era uma rádio muito importante que coordenava a rede composta pela Inconfidência e outras, mesmo sendo uma emissora privada.

No Rio de Janeiro, o Departamento de Propaganda e Turismo daquele estado espalhou alto-falantes pela cidade para que a população pudesse ouvir a Rádio Nacional. Em Minas Gerais, quem colocava os alto-falantes nas ruas era a emissora oficial do estado. A Rádio Inconfidência era uma organização midiática que contribuiria para a educação da nacionalidade, naquilo que unia e naquilo que representava as idiossincrasias brasileiras. A seleção era a expressão da nacionalidade, transmitida aos mineiros por aquela emissora estatal que se colocava como a "Voz de Minas". ${ }^{2}$

No final da década foram crescendo os programas esportivos. Em 1938, a emissora oficial de Minas tinha um noticiário esportivo que ia ao ar às 19 horas e tinha 15 minutos. O programa era intercalado com músicas e vinha antes do noticiário chamado de "Jornal Falado”. A Rádio Mineira e a Rádio Club do Rio de Janeiro, por exemplo, tinham noticiosos que tinham o mesmo nome, o "Onda Sportiva”. O programa da Rádio Mineira era dirigido pelo radialista Aulo Gouvêa. ${ }^{33} \mathrm{O}$ programa de esportes da Rádio Inconfidência era chamado de "Noticiário sportivo" e ocupava um espaço diminuto na programação, se comparado ao Jornal de notícias, que também tinha a característica de apresentar elementos da cultura e intercalava o programa com músicas e literatura, além de assuntos religiosos. ${ }^{34}$

No ano seguinte, em 1939, a Rádio Inconfidência fez parte de uma rede nacional de vinte e cinco emissoras (também lideradas pelas Rádio Nacional, a estação-chave, como era chamada na reportagem do jornal "A Noite"), que iria transmitir a Copa Roca daquele ano:

\begin{abstract}
A cidade e o Brasil aguardam, dentro de pouco mais de 24 horas, o sensacional embate entre argentinos e brasileiros, em porfia do centro de foot-ball sul-americano. Não se fala em outra coisa, mesmo nos círculos mais silenciosos... É a natural curiosidade por tudo que diga respeito ao cotejo de "cracks" da pelota amanhã, no stadium do Vasco da Gama, sobrevem uma pergunta: Qual a melhor maneira de acompanhar a pugna? Sem dúvida comparecer pessoalmente ao teatro da luta. Mas nem todos poderão ter este prazer. 50 mil pessoas que compareçam na grande praça de sports de São Januário nada significam ante a população da cidade e do Brasil. ${ }^{35}$
\end{abstract}

O jornalista parecia tentar justificar o fato de que a transmissão seria feita pelas emissoras de rádio. A mediação do rádio exigia a descoberta de outra maneira de experimentar o esporte, a criação de um imaginário da "pugna" através da oralidade proporcionada pelas transmissões feitas pelas ondas do rádio.

Vemos, portanto, o extraordinário alcance da iniciativa da Sociedade Rádio Nacional, alinhando em cadeia nada mais que 25 emissoras brasileiras, para a transmissão do empolgante jogo de amanhã. Oduvaldo Cozzi, o repórter que dispensa comentários relatará minuciosamente o desenvolvimento da partida, e as 25 emissoras retransmitirão sua reportagem, permitindo que qualquer brasileiro, colocado em qualquer ponto do território nacional, acompanhe o desenrolar da maior partida do football dos últimos tempos, tal o setor de alcance da cadeia de que é a estação chave a PRE-8 e que, pode se afirmar, representa a maior

32 A questão da relação do futebol com o Estado Novo foi abordada por vários estudiosos do esporte como no caso do livro organizado em 2006 (SILVA, 2006).

33 RADIO Novidades. Jornal dos Sports. Rio de janeiro, p. 3, 22 de julho 1939.

34RÁDIO. Jornal do Commércio. Rio de Janeiro, 9 julho de 1938.

35 A COPA Roca na maior cadeia de broadcasting do Brasil! A Noite, n. 9674, 14 Janeiro 1939. 
já reunida no Brasil. ${ }^{36}$

As fontes acima não só nos apontam apenas a formação das redes nacionais de transmissão, mas também para a integração do Estado Nacional brasileiro através das ondas de rádio. A rede que detectamos era composta tanto de rádios privadas quanto de estatais, como era o caso da Rádio Inconfidência. Grande parte delas estavam no Sudeste, no interior dos estados de São Paulo e Minas Gerais; também compunham a rede a Rádio Sociedade Gaúcha, de Porto Alegre, a Rádio Club de Pernambuco, a Rádio Tabajaras de João Pessoa, a Rádio Club do Ceará, a Rádio Club do Pará e outras em ondas curtas, como a Rádio Internacional, além da Rádio Club de Pernambuco que também transmitia em 49 metros, em ondas curtas.

A transmissão do jogo entre a seleção brasileira e a Polônia, realizada pela Rádio Clube do Rio de Janeiro em conexão com a rádio estatal de Minas Gerais parece ter tido significativo impacto na população da capital mineira:

\begin{abstract}
O povo vibrou intensamente sendo empolgado do maior entusiasmo quando foi anunciada a vitória final dos brasileiros. Cada lance do jogo era acompanhado de aplausos, num verdadeiro delírio popular. Toda população o desenrolar da sensacional partida, através da irradiação da Rádio Clube do Brasil que, em Minas Gerais foi retransmitida pela Rádio Inconfidência. ${ }^{37}$
\end{abstract}

Dois anos depois, em 1940, a Rádio Inconfidência retransmitia da emissora Mayrink Veiga (a cabeça da rede das transmissões da Copa Roca), os três jogos do evento que aconteceram em São Paulo e em Buenos Aires. Esta rede também era composta pela Record de São Paulo, Rádio Difusora de Petrópolis e Sociedade da Bahia. O speaker era o já famoso Gagliano Netto. ${ }^{38}$

O Estado Novo, como se sabe, soube usar o rádio a seu favor na construção de processos mediadores, tentando se constituir como uma nova hegemonia discursiva. As mediações passavam (como a nossa pesquisa anterior também demonstrou) pelas transmissões de eventos diretamente ligados ao Estado brasileiro, tanto os esportivos como os cívicos, populares ou religiosos. Também a Rádio Inconfidência realizava transmissões que eram retransmitidas nacionalmente pela rádio Nacional. O esporte passava então a compor (juntamente com a cultura e com a religiosidade), a noção de brasilidade e os sucessos da seleção nas Copas do Mundo dimensionavam positivamente o futebol na constituição da representação da nação.

A partir desse momento, a centralidade buscada pelo Estado Novo se manifestava através da seleção brasileira de futebol, ou Foot-Ball, como era chamado o esporte na época por alguns jornais. Portanto, poderíamos pensar no papel aglutinador da nação que o futebol adquiriu, por meio das rádios comerciais e estatais, como era o caso da Rádio Inconfidência em Minas. A partir da década de 1930, o rádio e futebol, assim como a música popular, passaram a ser instrumentos da construção de uma hegemonia que queria se impor naquilo que depois foi chamado de Varguismo.

\title{
CONSIDERAÇõES FINAIS
}

O rádio é um meio eletrônico cujo uso foi pensado para o espaço privado, mas as

36 Op.cit.

37 O REGOSIJO nos estados brasileiros. Jornal do Brasil, Rio de janeiro, n. 131, 7 junho, 1938.

38 GAZETA nos studios. Gazetas de notícias. Rio de janeiro, n. 35, p. 10, 13 fevereiro, 1940. 
condições dessa utilização dependeram, historicamente, do processo de desenvolvimento da sua indústria e, durante algumas décadas, as emissoras foram escutadas em praças públicas, quando essas organizavam as comemorações nos jogos da seleção brasileira, as festas populares e as festas cívicas. Nas décadas de 1930, 1940 e até mais, nos anos de 1950 e 1960, o rádio funcionou como um aglutinador das festas urbanas, interferindo veementemente nas relações de sociabilidade no espaço urbano ou conectando o mundo rural à urbanidade. $\mathrm{O}$ rádio também estava, portanto, direta e indiretamente no espaço público e sua linguagem oralizada, "esquentava" essa sociabilidade nas camadas mais pobres da população, nos mundos de trabalho e nos espaços de lazer.

Em relação ao futebol, as nossas fontes indicaram que podemos entender a sua construção como representação da nacionalidade na sua relação entrelaçada com o rádio, bem como o crescente processo de popularização desse esporte no Brasil. Não que o futebol fosse menos popular anteriormente, mas ele ganhou outra dimensão através do rádio, para além da sua escuta local, criando torcedores distanciados dos estádios.

O significado do que é cultura popular se constrói historicamente, como um processo. $\mathrm{Na}$ perspectiva dos Estudos Culturais e da História Social, principalmente aquela que pretende ver a história a partir da cultura das classes subalternas, a cultura popular é uma construção social, marcada pelas relações materiais que permitem a criação de representações do que o povo; essas representações são utilizadas e apropriadas por grupos que podem enquadrar a cultura em uma determinada visão de mundo, como fez o varguismo, principalmente a partir do Estado Novo. (HALL, 2003; WILLIAMS, 2011; GRAMSCI, 2017; THOMPSON, 2012).

Como podemos relacionar o futebol a essa perspectiva? Em primeiro lugar, é preciso perguntar como o futebol se tornou um esporte nacional e as condições dessa construção, tendo em vista a situação histórica vivenciada pelas pessoas, no seu dia a dia e pelo contexto político do momento. $\mathrm{O}$ futebol se tornou uma tradição popular, inventada nas tramas das redes de poder e do controle social, como afirma Eric Hobsbawn (1984). Para isso, temos que entrecruzar o desenvolvimento desse esporte ao desenvolvimento das indústrias midiáticas brasileiras e aos outros elementos culturais que, conjugados, constituem-se como uma nova hegemonia, quando são apropriados e redimensionados por um enquadramento sobre o que se passou a ser chamado de "cultura brasileira", a partir de 1930, pelo varguismo.

Desculpem-me um adendo aqui, nesse momento que já estamos caminhando para o fim da nossa discussão. Eu escrevo este texto no dia que Diego Armando Maradona morreu. O noticiário de hoje estimava a presença de mais de um milhão de pessoas nas ruas da capital argentina, em meio à pandemia do Covid-19, que tem matado milhões de pessoas pelo mundo. Eu, como um ator da história, também vivo o futebol mais do que tento descrevê-lo neste pequeno relato. Mas como a morte de Maradona me afeta? Que condições são criadas para que isso ocorra? Qual o papel dos meios de comunicação nesse processo? Que dimensões midiáticas ou, por outro lado, que outros tipos de mediações levaram tantas pessoas ao enterro desse que foi considerado um dos maiores jogadores de todos os tempos? Quem o elegeu dessa forma e em que condições, a ponto de se tornar tão popular?

Partimos da perspectiva de que a cultura popular é uma construção social e aos historiadores resta a difícil tarefa de tentar compreender um pouco dos sentimentos de uma determinada época, que se apresentam nos indícios que colhemos nas fontes. Maradona era 
uma representação desse sentimento ocasionado pelo futebol. Então, não pretendemos, ao longo do nosso tempo, apenas descrever os eventos das irradiações dos jogos, mas entender como as rádios descobriram que podiam ser populares através dessa modalidade que, cada vez mais, incorporava a atenção dos pobres.

Pudemos constatar, através de nossas fontes, que a formação das redes para as transmissões dos jogos da seleção levou o futebol para além da sua realidade local, criando uma experiência mediada para esse esporte e fazendo com ele se desenvolvesse em todo país. Liga-se a esse processo os usos realizados pelas estruturas de poder do Estado brasileiro, ao apropriarem do futebol e transformá-lo em um elemento da nacionalidade, ao tomá-lo como elemento aglutinador. Portanto, é uma relação dialética em que o Estado usa tanto o rádio quanto o futebol para a legitimação do projeto autoritário de modernização que se delineava no governo de Getúlio Vargas.

Mas, o mais importante, a nosso ver, é a maneira como as classes subalternas se apropriavam do futebol de uma outra maneira, nas ruas, nas praças, na audição coletiva através dos alto-falantes. Se aproximarmos tal vivência do nosso tempo, poderíamos pensar, por exemplo, na prática de levar os pequenos rádios para os estádios, uma simbiose entre as várias mediações que podem acontecer entre o futebol e essa pequena caixinha de comunicação chamada rádio, ainda muito presente. E aí a História Oral poderia nos ajudar muito nesse aspecto, o de desvendar essa trama da história. 


\section{REFERÊNCIAS BIBLIOGRÁFICAS}

AMARAL, Daniel Venâncio de Oliveira; COUTO, Euclides de Freitas. O futebol no Oeste de Minas: Os encontros intermunicipais e os sentidos das práticas esportivas em Oliveira (1916-1925). Revista Maracanã. Rio de Janeiro, n. 21, p. 105-124, maio-agosto, 2019.

A MOMENTOSA questão da irradiação das partidas de futebol. Diário Carioca, Rio de Janeiro, n. 308, p.6, 26 julho de 1929. Disponível em: http://memoria.bn.br/DocReader/093092_01/3593. Acesso em: 24 nov. 2020.

A IRRADIAÇÃO do jogo. Correio Paulistano. São Paulo, n. 25226, p. 20, 5 junho, 1938. Disponível em: http://memoria.bn.br/DocReader/090972_08/24373. Acesso em: 24 nov. 2020

AZEVEDO, Lia Calabre. A era do Rádio. Rio de Janeiro, Jorge Zahar editor, 2002.

AZEVEDO, Lia Calabre. No tempo do rádio: radiodifusão e cotidiano no Brasil, 1923-1960. 1v. Tese (Doutorado em História) Curso de História da Universidade Federal Fluminense, Niterói, Rio de Janeiro, 2002. $276 \mathrm{f}$.

SEM fio. A noite. Rio de Janeiro, n. 6354, p. 4, 28 julho de 1929. Disponível em: http://memoria. bn.br/docreader/348970_02/26201. Acesso em: 24 nov. 2020.

CAMPEONATO mundial de Football. Correio da manhã. Rio de Janeiro, n.10906, p. 10, 12 de julho de 1930. Disponível em: http://memoria.bn.br/DocReader/089842_04/2841. Acesso em: 24 nov. 2020.

CAPELATO, Maria Helena Rolim. Multidões em Cena: propaganda política no varguismo e no peronismo. 2.ed. - São Paulo :Editora UNESP, 2009.

CORREA, Luiz Otávio Rádio Inconfidência, memórias e representações da nação: Mediações culturais em uma emissora estatal (1970-1991). Orientador: Juniele Rabelo de Almeida. Tese (doutorado). Programa de Pós-graduação em História, Universidade Federal Fluminense, Niterói, 2020. 407 f. : il.

COTA, Leide Mara da Conceição. Rádio, educação e formação da identidade nacional: um estudo da rádio inconfidência de Minas Gerais (1936-1945). $221 \mathrm{f}$. Dissertação (Programa de Pós-Graduação em Educação, Conhecimento e Inclusão Social). UFMG, Belo Horizonte, 2016.

COUTO, Euclides de Freitas. Da ditadura à ditadura: uma história política do futebol brasileiro (1930-1978). Niterói: Editora da UFF, 2014.

EM FRENTE ao Correio da Manhã. Correio da manhã. Rio de Janeiro, n. 11662, 11 dezembro de 1932. Disponível em: http://memoria.bn.br/DocReader/089842_04/14362. Acesso em: 24 nov. 2020.

FECHARAM cedo às repartições. Correio da manhã. Rio de Janeiro, N.13373, p.6. 15 junho de 1938. Disponível em: http://memoria.bn.br/DocReader/089842_04/46777. Acesso em 25 nov. 2020.

GAZETA nos studios. Gazetas de notícias. Rio de Janeiro, n. 35, p. 10, 13 fevereiro de 1940. Disponível em: http://memoria.bn.br/DocReader/103730_07/422. Acesso em: 24 nov. 2020.

GRAMSCI, Antônio. Cadernos do Cárcere. Os intelectuais. O princípio educativo. Jornalismo. Vol. 2. Trad. Carlos Nelson Coutinho. Rio de Janeiro, civilização brasileira, 2004.

GUERRA, Márcio de Oliveira. Rádio x TV: O jogo da narração - A imaginação entra em campo e seduz o torcedor. Rio de Janeiro, 2006. Tese (Doutorado em Comunicação) - Escola de 
Comunicação, Universidade Federal do Rio de Janeiro, Rio de Janeiro, 2006.

HALL, Stuart. Da diáspora. Identidades e mediações culturais. Belo Horizonte: UFMG, 2003.

HOBSBAWM, Eric. RANGER, Terence. (orgs.). A invenção das tradições. - Rio de Janeiro: Paz e Terra, 1984. Págs. 9-23.

IRRADIAÇÃO do Match. Correio da Manhã, Rio de janeiro, n. 11654, 2 dezembro de 1932. Disponível em: http://memoria.bn.br/docreader/089842_04/14242. Acesso em: 24 nov. 2020 IRRADIAÇÃO será feita em 25 emissoras. Pequeno Jornal: Jornal Pequeno. Pernambuco, n.133, 15 junho de 1938. Disponível em: http://memoria.bn.br/DocReader/800643/61210. Acesso em: 24 nov. 2020.

LE GOFF, Jacques. História e memória. Campinas: Editora UNICAMP, 1996. p. 538. Tradução: Irene Ferreira, Bernardo Leitão, Suzana Ferreira Borges.

LUGUORI, Guido; VOZA, Pascale. Dicionário Gramsciniano, 1926-1937. Trad. Ana Maria Chiarini et al. São Paulo: Boitempo, 2017

MAIS um goal da Radio Club do Brasil. Jornal do Brasil, Rio de Janeiro, ano 97, n. 179, p. 13, 27 julho, 1929. Disponível em: http://memoria.bn.br/DocReader/030015_04/77239. Acesso em: 24 nov. 2020.

MARTÍN-BARBERO. Jesús. Dos meios às mediações. Tradução de Ronald Polito e Sérgio Alcides. Rio de Janeiro: Editora UFRJ. 1997. p. 248.

MISCELÂNEA sportiva. Correio da manhã, Rio de Janeiro, n.11127, p. 8.28 de março de 1931. Disponível em: http://memoria.bn.br/DocReader/089842_04/6406. Acesso em: 24 nov. 2020.

MOURA, Rodrigo C. B. $\mathbf{O}$ amadorismo, o profissionalismo, os sururus e outras tramas: $\mathbf{O}$ futebol em Belo Horizonte na década de 1930. In: O futebol nas Gerais. O futebol nas Gerais / Silvio Ricardo da Silva, José Alfredo de O. Debortoli, Tiago Felipe da Silva, organizadores. - Belo Horizonte : Editora UFMG, 2012.

O CAMPEÃO dos speakeres. Carioca. Rio de Janeiro, n. 145, p. 40. http://memoria.bn.br/ DocReader/830259/8791

O INTERESSE nos Estados. Jornal do Commércio, p. 9, 15 de junho de 1938. Disponível em: http://memoria.bn.br/DocReader/364568_12/54707

O REGOSIJO nos estados brasileiros. Jornal do Brasil, Rio de janeiro, n. 131, 7 junho de 1938. Disponível em: http://memoria.bn.br/DocReader/030015_05/84932. Acesso em: 24 nov. 2020.

PERÁCIO, Niginho e Zezé falarão, hoje, com suas famílias. Jornal A Noite. 15 julho de 1938. Disponível em: http://memoria.bn.br/DocReader/348970_03/54765

POOL, Ithiel de Sola. Discursos y sonidos de largo Alcance. In:Historia de la comunicacion: de la imprenta a nuestros dias. Raymond Willians(org.) Vol. 2. Barcelona: Bosch casa editorial. 1992.

RÁDIO. Jornal do Commércio. Rio de Janeiro, 9 julho de 1938. Disponível em: http://memoria. bn.br/DocReader/364568_12/55078. Acesso em: 24 nov. 2020.

A COPA Roca na maior cadeia de broadcasting do Brasil! A Noite, n. 9674, 14 Janeiro 1939. Disponível em: http://memoria.bn.br/DocReader/348970_03/60651. Acesso em: 24 nov. 2020.

SEM fio. A noite. Rio de Janeiro, n. 06509, p. 4, 28 de dezembro de 1929. Disponível em: http:// 
memoria.bn.br/DocReader/348970_02/27409. Acesso em: 24 nov. 2020

SEM fio. Correio da manhã, Rio de Janeiro, n. 11601, 2 outubro 1932. Disponível em: http:// memoria.bn.br/DocReader/089842_04/14090. Acesso em: 24 nov. 2020.

SILVA, Francisco Teixeira da; SANTOS, Ricardo Pinto dos. Memória social dos esportes: Futebol e política: a construção de uma identidade nacional. Rio de Janeiro, Mauad Editora: Faperj, 2006.

SOARES, Edileuza. A Bola no ar: Rádio Esportivo em São Paulo. São Paulo, Summus editorial, 1994.

THOMPSON, E. P. As peculiaridades dos ingleses e outros artigos. $2^{\circ}$. Ed. Campinas, SP:

Editora Unicamp, 2012.

WILLIAMS, Raymond. Cultura e Materialismo. Trad. André Glaser. São Paulo: Editora Unesp, 2011. 